Цыкора Анна Владимировна, Донской государственный строительный университет, кандидат юридических наук, ttanneta@ mail.ru, 89185203871,

Tsykora Anna Vladimirovna, Don State University of Civil Engineering, PhD in Law, ttanneta@ mail.ru, 89185203871,

Суколенко Екатерина Александровна,

ФГКОУ ВО «Ростовский юридический институт Министерства внутренних дел Российской Федерации», начальник учебного отдела, кандидат юридических наук, esukolenko@ mvd.ru, 8-908-500-75-21,

Sukolenko Ekaterina Aleksandrovna, FGKOU VO "Rostov Institute of Law of the Ministry of Internal Affairs of the Russian Federation", head of the training department, candidate of jurisprudence, esukolenko@mvd.ru,8-908-500-75-21,

Аннотация. Коррупция представляет собой системную угрозу самого высокого порядка для существующих в Российской Федерации общественных отношений. Системность обусловленной проблемы характеризуется тем, что проблема коррупции подразумевает eе нацеленность на разрушение абсолютно всех социальных институтов (общественные объединения, движения, партии) и институтов государственной власти (законодательные исполнительные и судебные органы).

Ключевые слова: коррупционные проявления, коррупция, уголовный кодекс, социальное явление, противодействие коррупции, уголовно-правовая политика, коррупционная преступность, преступления коррупционной 
направленности, посредник, взяткодатель, взяткополучатель, пресечения преступлений коррупционной направленности, профилактика

Annotation. Corruption is a systemic threat of the highest order for the social relations existing in the Russian Federation. The consistency of the caused problem is characterized by the fact that the problem of corruption implies its focus on the destruction of absolutely all social institutions (public associations, movements, parties) and state institutions (legislative executive and judicial bodies).

Key words: corruption manifestations, corruption, criminal code, social phenomenon, anti-corruption, criminal law policy, corruption or crime, or crimes of a corruption orientation, mediator, briber, briber, prevention of crimes of corruption, prevention

СОВРЕМЕННЫЕ ТЕНДЕНЦИИ УГОЛОВНО-ПРАВОВОЙ

ПОЛИТИКИ РФ В СФЕРЕ ПРОТИВОДЕЙСТВИЯ КОРРУПЦИИ: УГОЛОВНО - ПРАВОВЫЕ МЕРЫ ПРОТИВОДЕЙСТВИЯ КОРРУПЦИИ

\section{MODERN TRENDS OF CRIMINAL LEGAL POLICY OF THE RUSSIAN FEDERATION IN THE SPHERE OF COUNTERACTION OF CORRUPTION: CRIMINALLY - OR LEGAL FOR MEASURES OR COUNTERACTION OF CORRUPTION}

Деятельность органов законодательной власти российского государства, направленная на активизацию уголовно-правовой политики в сфере борьбы с коррупцией, представляющей угрозу национальной безопасности, свидетельствует о том, что данная проблема является острой, требующей пристального внимания. Стратегия борьбы в этом направлении реализуется всеми доступными средствами уголовно-правового инструментария. Вводятся редакционные правки в уже существующие 
нормы уголовного права, Уголовный закон дополняется новыми составами, призванными к борьбе с данным негативным социальным явлением, формируется база нормативно-правовых актов, создающих условия активного, планомерного противодействия коррупционным проявлениям. Такая активность органов государственной власти вполне обоснована, так как в условиях современности коррупция пронизывает все области жизнедеятельности и посягает на наиболее важные общественно значимые отношения, поэтому регулирование этого вопроса нормами уголовного законодательства представляется единственно правильным. Как справедливо отмечают авторы, изучающие вопросы коррупционного поведения граждан, прослеживается негативная тенденция к увеличению коррупционных проявлений, к формированию новых видов коррупции, не подпадающих в сферу влияния закона. Это, в свою очередь, увеличивает воздействие отрицательного влияния коррумпированности населения и органов власти, провоцирует ситуации реализации преступных замыслов антисоциальных типов личности. Население, ощущающее на себе столь негативные процессы наращивает недовольство к власти, все более негативно относится к праву, разочаровывается в системе государственных органов, не доверяет правоохранительной системе. Такое положение обуславливает торможение процессов развития в столь важных социальных сферах как экономика, сфера обслуживания населения, политика. А, как известно, нестабильность в политике влечет за собой разлад в идеологии, которую исповедуют граждане. Проживающие на территории многонациональных государств ${ }^{1}$.

Многие исследования последних лет посвящены вопросам противодействия коррупционным проявлениям. Уровень опасности коррупции в том или ином государстве определяется с учетом индекса ее восприятия. Каждый год эксперты оценивают по ряду показателей этот индикатор и делают соответствующие рейтинги коррумпированности

\footnotetext{
${ }^{1}$ Авдеев В.А., Авдеева О.А. Стратегические направления противодействия коррупции в РФ // Российская юстиция. 2016. № 7. С. 19.
} 
государств. Так, по итогам 2016 года, полученные характеристики позволили определить место российской Федерации в этом рейтинге. Россия оказалась на сто тридцать первом месте из ста семидесяти шести стран, которые были обследованы на предмет коррупционной составляющей. Этот показатель прямо указывает на то, что качественность проводимых антикоррупционных мероприятий в нашем государстве требует незамедлительного совершенствования.

Статистика вещь упрямая, но в случае со статистическими данными, определяющими уровень коррупции в стране, даже цифры не могут дать однозначный ответ. С одной стороны наблюдается рост преступлений коррупционной направленности на 1,4\% по итогам 2016 года, а с другой стороны в средствах массовой информации приводятся данные, наглядно иллюстрирующие сокращение количества зарегистрированных преступлений коррупционной направленности. Соответственно, увеличению подлежал до 1,52\% в 2016 году относительный показатель зарегистрированных преступлений коррупционной направленности. Удельный вес нанесенного в 2016 году преступлениями коррупционной направленности материального ущерба составил 7,8\% от общей суммы причиненного ущерба совершенными преступлениями в целом².

Наметившаяся в условиях глобализации международной жизни трансформация коррупции как социально- правового явления неизбежно детерминировала характер и виды преступлений коррупционной направленности. Вследствие этого особую значимость при определении мер уголовно- правовой политики в сфере противодействия коррупции приобретает осмысление теоретико- методологических основ данного явления, прежде всего в части разработки единообразных подходов к дефиниции коррупции. Сложность установления границы между указанными

\footnotetext{
${ }^{2}$ Авдеев В.А., Авдеева О.А. Новые тенденции уголовно-правовой политики РФ в сфере противодействия преступлениям коррупционной направленности // Российская юстиция. 2017. № 5. С. 2.
} 
коррупционными деяниями предопределяется различным значением используемых дефиниций в международном и национальном праве. Плюрализм различных национальных правовых систем обусловил неоднозначные подходы к законодательному определению коррупции, коррупционной преступности, преступлений коррупционной направленности и т.д.

Распространенность коррупционного элемента во всех сферах жизнедеятельности граждан становится настолько масштабным, что требуется незамедлительная реакция в виде совершенствования уголовного законодательства, так как ныне действующий закон не всегда охватывает все формы проявления преступлений указанной направленности. Так, появившиеся в последние годы так называемые посредники между взяткодателем и взяткополучателем представляют криминологически негативную категорию граждан, так как они способствуют совершению преступлений, а сами, довольно часто остаются безнаказанными. Это порождает в сознании общества то обстоятельство, что данная деятельность остается за рамками коррупции. На самом же деле это не так, в подтверждение можно привести ст. 291.1 УК РФ, закрепившую самостоятельную ответственность посредников как лиц, совершающих общественно опасное деяние. Таким образом, система правовых мер противодействия коррупционным проявлениям является важным элементом в системе противодействия и профилактики этого негативного социального явления, а ведомственные нормативно-правовые акты способствуют реализации функций предупреждения. Например, в соответствии с Указанием Генпрокуратуры России № 797/11, МВД России № 2 от 13.12.2016 «О введении в действие перечней статей Уголовного кодекса Российской Федерации, используемых при формировании статистической отчетности»³,

\footnotetext{
${ }^{3}$ Указание Генпрокуратуры России № 797/11, МВД России N 2 от 13.12.2016 «О введении в действие перечней статей Уголовного кодекса Российской Федерации, используемых при формировании статистической отчетности» Документ предоставлен КонсультантПлюс (дата обращения: 12.03.2018).
} 
преступления, обладающие коррупционной составляющей формируют две основные группы, в основу деления которых положен умысел лица, на совершение противоправного деяния. Первую группу образовывают коррупционные деяния, для реализации которых нет необходимости соблюдать какие-либо условия. Ко второй группе относятся так называемые условные преступления, т.е. такие, для которых характерна коррупционная составляющая, с обязательным соблюдением условий, способствующих преступному поведению. Не требующие каких-либо условий преступления коррупционной направленности получили закрепление в следующих статьях Уголовного кодекса РФ: ст. 141.1, 184, п. «б» ч. 3 ст. 188, ст. 204, 204.1, 204.2 , п. «а» ч. 2 ст. 226.1 , п. «б» ч. 2 ст. 229.1 , ст. $289,290,291,291.1,291.2$ УК РФ.

Преступления, относящиеся ко второй группе, обуславливаются в карточках статистических отчетов отметками следующего содержания: 1) общественно опасные деяния, подпадающие под признаки перечня, указанные в статистической карточке с обязательной отметкой о наличии коррупционного элемента: ст. 174, 174.1, 175, ч. 3 ст. 210; 2) преступления, которые расположены в перечне на основании ратифицированных договоров с другими государствами, при обязательном учете в статистической карточке коррупционного проявления: ст. 294, 295, 296, 302, 307, 309; 3) преступные деяния, которые имеют корыстную направленность и подпадают под категорию коррупционных: п.п. «а» и «б» ч. 2 ст. 141, ч. 2 ст. 142, ст. 170, 201, 202, ч. 2 ст. 258.1 , ст. 285, 285.1, 285.2, 285.3, ч.ч. 1 и 2 и п. «В» ч. 3 ст. 286, ст. 292, ч.ч. 2 и 4 ст. 303, ст. 305; 4) посягательства, совершаемые должностными лицами, обладающими функцией представителя власти, организационно-распорядительными функциями или административнохозяйственными, а также лица, не обладающие признаками должностного лица, но реализующие управленческие функции в негосударственных организациях, осуществляющих свою деятельность в целях получения прибыли: ч. 4 ст. 188 , п. «В» ч. 3 ст. 226 , ч. 3 ст. 226.1 , ч. 2 ст. 228.2 , п. «В» ч. 
2 ст. 229, ч.ч. 3 и 4 ст. 229.1; 5) преступления, которые совершаются лицами, указанными в пункте 4 нашего исследования, но при этом имеющие корыстную мотивацию: ч.ч. 3 и 4 ст. 183, п. «б» ч. 4 ст. 228.1, п. «б» ч. 2 ст. 228.4 , ч. 3 ст. 256 , ч. 2 ст. 258 , ч. 3 ст. 258.1 , п. «В» ч. 2 и ч. 3 ст. 260 , ч.ч. 1 и 3 ст. 303, ст. 322.1, 322.2, 322.3; 6) преступления коррупционной направленности, которые могут относится к анализируемому перечню только при условии, что уголовное дело по данному факту было возбуждено до 01.01. 2013 г.: п. «б» ч. 3 ст. 228.1; 7) преступления, входящие в перечень коррупционных проявлений, совершенные должностными лицами и управленцами в коммерческих структурах при использовании своего служебного положения: ч.ч. 3, 4, 5, 6 и 7 ст. 159, ч.ч. 3 и 4 ст. 159.1, ч.ч. 3 и 4 ст. 159.2 , ч.ч. 3 и 4 ст. 159.3 , ст. 159.4 , ч.ч. 3 и 4 ст. 159.5 , ч.ч. 3 и 4 ст. 159.6, ч.ч. 3 и 4 ст. 160, ч.ч. 3 и 4 ст. 229; 8) Преступления, которые сами по себе не содержат в себе коррупционной составляющей, но способствующие совершению актов коррупции: ст. 159, 159.1, 159.2, 159.3, 159.4, 159.5, 159.6 (за исключением случаев, указанных в п. 3.6), ст. 169, 178, $179^{4}$.

Из приведенных данных, характеризующих классификационные группы преступлений коррупционной мотивации, можно выделить то обстоятельство, что абсолютное большинство преступлений, имеющих коррупционную составляющую реализуются из первой группы, то есть группы, без дополнительных условий. Эти преступления находят свое отражение в соответствующих статьях УК РФ, размещенных в главе 19, 22 25 и 30. Также, с учетом изложенного можно сформулировать понятие коррупционного преступления, согласно которому оно формируется из объединения противоправных, корыстных умышленных деяний лиц, обладающих признаками должностного лица, направленных на приобретение выгод имущественного характера, либо реализующих свои функции в целях

\footnotetext{
${ }^{4}$ Указание Генпрокуратуры России № 797/11, МВД России N 2 от 13.12.2016 «О введении в действие перечней статей Уголовного кодекса Российской Федерации, используемых при формировании статистической отчетности» Документ предоставлен КонсультантПлюс (дата обращения: 12.03.20018).
} 
необоснованного предоставления привилегий как для себя самого, так и для других лиц. Данное определение позволяет нам наметить пути дальнейшей реализации политики государства, в деле борьбы с коррупцией.

Итак, безусловно, важнейшее место в этом противоборстве отведено законодательной базе, без грамотности составления которой трудно представить себе возможность качественного взаимодействия всех структур в этой деятельности. В связи с изложенным, полагаем возможным и необходимым закрепить в соответствующих Федеральных законах понятие коррупции, обозначить в нем основные признаки, характеризующие данное «зло». Вполне допустимо, согласится с мнением тех авторов, которые видят необходимость в разработке понятия «состава коррупционных правонарушений». Это послужи хорошей превентивной мерой на пути к реализации более тяжких, уголовно-наказуемый деяний, в основе которых коррупционная направленность Усовершенствование составов коррупционных преступлений, уточнения по многим из них момента окончания также вплетается в стройную канву данного направления противодействия.

Совершенно справедливо осуществлять данную борьбу с учетом основополагающих принципов, основываясь на которых можно рассчитывать на успех в этом не простом деле. Среди таких основ можно отметить следующие: усиление роли взаимодействия государства с общественными организациями, с отдельными гражданами, а также с организациями, имеющими статус международных. Такое сотрудничество приведет к формированию новых идей, получения бесценного опыта противодействия коррупции, имеющегося в арсенале зарубежных государств и будет способствовать снижению уровня коррупции в нашей стране. Конечно, без реализации предупредительных мер внутри страны, добиться положительных результатов на международном уровне будет нелегко, поэтому важно пролонгировать публичность и прозрачность работы органов государственной власти, обеспечивать всеми правовыми средствами 
неотвратимость наступления государственной реакции в виде наказания за коррупционные деяния. Работа, направленная на противодействие коррупции должна реализовываться согласованной, причем это должно выражаться в единстве концептуальных положений экономических, политико- правовых, социальных и мер организационного характера. Данные меры должны планомерно реализовываться на всех уровнях власти, так как «однобокое» развитие, например, социальных мер, не приведет к желаемому результату. Федеральные органы государственной власти должны тесно взаимодействовать с органами власти субъектов РФ, а те, в свою очередь оценивать работу в этом направлении нижестоящих субъектов подчинения. Правотворческий уровень противодействия может быть эффективным только в том случае, если произойдет комплексны пересмотр отраслевого законодательства в целом, а не по отдельным его звеньям ${ }^{5}$.

В первую очередь необходимо уделить внимание вопросу отграничения норм уголовного и административного права в контексте коррупционных проявлений. Отличие данных норм в первую очередь проводится по степени общественной опасности содеянного, а так как при установлении последствий законодатель использует оценочные категории, иногда это вызывает определенные затруднения. Например, при злоупотреблении должностными полномочиями обязательным последствием деяния является причинение существенного вреда законным интересам. Если нет существенности в причиненных последствиях, имеет место иное правонарушающее поведение в области и, но не уголовно-наказуемое. Поэтому очень важное значение приобретает правильная квалификация деяний, подпадающих под признаки коррупционных преступлений. К примеру, в Определении Судебной коллегии по уголовным делам Верховного Суда РФ от 16.10.2014 № 46-УД14-8 изменению квалификации с ч. 4 ст. 159 УК РФ на ч. 3 ст. 159.4 УК РФ подлежали мошеннические

\footnotetext{
${ }^{5}$ Авдеев В.А. Оптимизация целей наказания в контексте предупреждения преступности // Криминологический журнал Байкальского государственного университета экономики и права. 2013. № 2. С. 41.
} 
действия лица, совершившего данное преступление с заведомо направленным умыслом на невыполнение обязательств, взятых по договору, в коммерческой деятельности ${ }^{6}$.

Как известно, правильная юридическая оценка деятельности лица влечет за собой и назначение справедливого, соразмерного содеянному наказания. В области также встречаются трудности, связанные с назначением справедливого, основанного на принципе соразмерности и справедливости наказания. К сожаление и такой принцип, как принцип равенства граждан перед законом и судом тоже становится простой декларацией, а не условием реализации уголовной ответственности. Так как коррупция проявляется в деятельности должностных лиц, то и обладают эти граждане определенными связями в сфере взаимоотношения граждан с государством, соответственно и поблажки, и «закрывание глаз» на некоторые вещи, и несоразмерно содеянному минимальные сроки наказания. Все это присутствует в действительности. Противостоять этому возможно при формировании кадрового аппарата, изначально набирая на государственные должности сотрудников, прошедших жесткий отбор, способны к волевым решениям, уважающим закон и правопорядок. Тогда поколебать их мнению путем предложений, имеющих корыстный характер будет непросто, а в отдельных случаях невозможно.

Размышляя о профилактических мероприятиях невозможно не затронуть проблему процесса установления и пресечения преступлений коррупционной направленности. Современные методы предупреждения и выявления фактов коррупции не соответствуют в полной мере тем ее проявлениям, которые мы наблюдаем в современном обществе. В связи с этим возможно усовершенствование имеющихся методов путем увеличения объема административного ресурса, который может быть представлен всем сотрудникам государственных учреждений в том, что они имеют право сообщать о фактах коррупции своему руководству, без достоверных

\footnotetext{
${ }^{6}$ Бюллетень Верховного Суда Российской Федерации. 2015. № 6.
} 
сведений и доказательств. Конечно, это не повлечет для «подозреваемого» юридических последствий, но заставит обратить на него внимание и возможно, будут выявлены какие-либо реальные факты коррупционного поведения. Разработка методики выявления коррупционно направленных «чиновников», предусмотрение такой меры как конфискация имущества в случаях, когда имущество коррупционера добыто заведомо преступным путем, введение уголовной ответственности юридических лиц, и в частности в том аспекте, где коммерческие предприятия участвуют в коррупционных цепях, введение в оборот свода правил поведения должностных лиц, относящихся к публичной власти, наконец, открытость финансовых потоков, обеспечивающих оборот денежных средств в сфере государственных закупок.

Подводя итого исследуемого вопроса, следует еще раз отметить, что реализация современной уголовно-правовой политики против коррупции имеет основной тенденцией формирование взаимодействия законотворчества внутри всех отраслей права, регулирующих вопросы противодействия коррупции с мерами профилактического характера. Это сочетание будет способствовать стремлению общества повышать свой культурный, профессиональный, этический потенциал и позволит сформировать в обществе нетерпимость к коррупции. Со своей стороны, механизмы правового воздействия, включающие в себя просветительскую пропаганду нетерпимости к коррупции, повышение социальной активности граждан, усиление роли общественности в правовых вопросах, внедрение большего объема контролирующей функции власти, регулирование вопросов конфликта интересов будут значительным образом препятствовать росту коррупции в стране.

1. Авдеева Е.В. Механизм уголовно-правового регулирования свободы личности в Российской Федерации: Автореф. дис. ... канд. юрид. наук: 
12.00.2008. Уральская государственная юридическая академия. Екатеринбург, 2013.

2. Авдеева Е.В. Правовые основы обеспечения свободы личности в России // Известия Байкальского государственного университета. - 2013. - № 3.

3. Бондаренко С.В. Коррумпированные общества. Ростов-на-Дону, 2002.

4. Бочарников И.В. Зарубежный опыт противодействия коррупции // Аналитический вестник Аналитического управления Аппарата Совета Федерации Федерального Собрания Российской Федерации. - 2007. - № 6

5. Быков А.В. Коррупционная преступность в системе органов местного самоуправления: Автореф. дис. ... канд. юрид. наук. Екатеринбург, 2016.

6. Гоц Е.В. Государственно-правовые основы борьбы с коррупцией в Российской Федерации // Новый юридический журнал. - 2014. - № 2.

7. Гриб В.В. Актуальные проблемы нормативного закрепления системы субъектов общественного контроля в Российской Федерации // Конституционное и муниципальное право. - 2016. - № 1.

8. Дашков Г.В. Зарубежные модели борьбы с преступностью в России // Право и государство: теория и практика. - 2015. - № 4.

9. Зорькин В.Д. Коррупция как угроза стабильному развитию общества // Журнал российского права. - 2012. - № 7.

10.Иноземцева Л.Н. Экономические последствия коррупции // Преодоление коррупции - главное условие утверждения правового государства / под общ. ред. А.И. Комарова. М., 2009.

11.Квон Д.А. Политическая коррупция: понятие, цели, субъекты // Власть. -2015 . - № 7 .

12.Коррупция: природа, проявления, противодействие / под общ. ред. Т.Я. Хабриевой. М., 2015.

13.Мельникова Н.А., Крижановский С.В. Конфликт интересов в системе профилактики коррупции на правоприменительной службе // Российский следователь. - 2015. - № 23. 